\title{
Longitudinal changes of circadian leptin, insulin and cortisol plasma levels and their correlation during refeeding in patients with anorexia nervosa
}

\author{
Stephan Herpertz ${ }^{1}$, Norbert Albers ${ }^{2}$, Richard Wagner ${ }^{3}$, Barbara Pelz ${ }^{1}$, Werner Köpp ${ }^{4}$, Klaus Mann ${ }^{3}$, \\ Werner F Blum ${ }^{5,6}$, Wolfgang Senf ${ }^{1}$ and Johannes Hebebrand ${ }^{7}$ \\ ${ }^{1}$ Clinic of Psychotherapy and Psychosomatics, University of Essen, Postfach 103043, D-45030 Essen, Germany, ${ }^{2}$ Children's Hospital, \\ University of Bonn, Germany, ${ }^{3}$ Division of Endocrinology, Department of Internal Medicine, University of Essen, Germany, \\ ${ }^{4}$ Department of Psychosomatics and Psychotherapy, Benjamin Franklin University Berlin, Germany, ${ }^{5}$ Children's Hospital, \\ University of Gießen, Germany, ${ }^{6}$ Lilly Deutschland GmbH, Bad Homburg, Germany, ${ }^{7}$ Department of Child and Adolescent Psychiatry of the \\ University of Marburg, Germany \\ (Correspondence should be addressed to S Herpertz, Email stephan.herpertz@uni-essen.de)
}

\begin{abstract}
Objective: To study the longitudinal changes in plasma levels of leptin, insulin and cortisol during the transition from the state of starvation to the state of refeeding focussing on diurnal secretion characteristics and their temporal relationships.

Design: Leptin, insulin and cortisol were measured every $2 \mathrm{~h}$ for $24 \mathrm{~h}$ during acute starvation (T1). Sampling was repeated after reaching half the target-body mass index (BMI) (T2) and again at targetBMI $\left(17.5 \mathrm{~kg} / \mathrm{m}^{2}\right.$; T3). The temporal relationships between the diurnal secretion patterns were assessed by cross-correlation analysis.

Results: Although BMIs at T1 were uniformly low, leptin levels varied widely within a range clearly below normal levels $(0.03-1.7 \mu \mathrm{g} / \mathrm{l})$. With increasing body fat during the course of refeeding, mean leptin levels increased from $0.64 \mu \mathrm{g} / \mathrm{l}$ (range: $0.27-1.73 \mu \mathrm{g} / \mathrm{l}$ ) (T1) to $1.61 \mu \mathrm{g} / \mathrm{l}$ (range: $0.36-4.2 \mu \mathrm{g} / \mathrm{l}$ ) (T2) and to $3.67 \mu \mathrm{g} / \mathrm{l}$ (range: 0.7-9.8 $\mu \mathrm{g} / \mathrm{l}$ ) (T3). Circadian leptin secretion patterns showed maximal values uniformly around $0200 \mathrm{~h}$ and minimal values around $0800 \mathrm{~h}$ at all stages of the study. At all three weight levels, plasma leptin levels were highest between midnight and the early morning hours and lowest around the late morning hours. Refeeding neither profoundly changed secretion patterns of leptin nor did it change the positive, time-delayed relationship between leptin and insulin with increments in insulin secretion preceding those of leptin by $6 \mathrm{~h}$. A temporal relationship between leptin and cortisol could not be demonstrated in the state of semistarvation but emerged after a substantial weight gain; at that time, leptin increases preceded cortisol increases by $8 \mathrm{~h}$.

Conclusions: Absolute leptin, insulin and cortisol levels are profoundly changed during starvation in anorectic patients, while refeeding, paralleled by a BMI gain, reverses these changes. During refeeding the relationship between leptin and cortisol changed profoundly, showing no significant correlation in the state of starvation, whereas at T3 after refeeding a strong inverse relationship could be observed. Leptin and insulin did not correlate significantly at any of the three stages studied.
\end{abstract}

European Journal of Endocrinology 142 373-379

\section{Introduction}

The $o b$ gene encodes leptin, which is a protein secreted specifically by adipocytes and involved in body weight regulation $(1,2)$. In the mouse, as well as in humans, defects in the leptin coding sequence $(o b / o b)(1-5)$ or the leptin receptor/signalling system $(d b / d b)(6,7)$ cause severe obesity. Leptin is not only of interest in the pathogenesis of obesity, but also at the other extreme of body weight, in anorexia nervosa (AN). Fasting leads to a rapid decrease in circulating leptin levels which sets in prior to weight loss $(8-10)$. Serum leptin levels are correlated with weight and percentage body fat in normal- and overweight probands (11). Studies on the exact relationship of leptin to body weight in AN produced contradictory findings (1216). In humans, serum leptin levels show a circadian rhythm (17). Whereas in the study of Sinha et al. (17) the circadian pattern did not appear to be influenced by meal ingestion and meal-related increases in circulating insulin and glucose levels, we could demonstrate a clear temporal relationship 
not only of insulin but also of cortisol with leptin in humans of different weight categories (18). These findings were in line with the results of former studies in rats (19).

Secretion of leptin occurs in a pulsatile manner and serum leptin levels show an inverse relationship to those of adrenocorticotropic hormone (ACTH) and cortisol (20). Furthermore the ultradian fluctuations in leptin levels show pattern synchronicity with those of both luteinizing hormone (LH) and estradiol (21). Recently, we compared diurnal secretion characteristics of leptin, insulin and cortisol of anorectic patients prior to refeeding, and in the state of refeeding, and in underand normal-weight controls (18). Beside exceedingly low plasma leptin levels, semistarvation in the non-refed anorectic patients was associated with a qualitative alteration in the circadian rhythm of leptin and cortisol levels and an alteration in the temporal coupling between cortisol and leptin. Increments in insulin secretion preceded those of leptin by $4-6 \mathrm{~h}$ in both anorectic patients and in controls. However, leptin levels increased $4 \mathrm{~h}$ prior to those of cortisol in controls and in refed patients, whereas in the non-refed patients cortisol increased prior to leptin. In the present study we investigated the intra-individual dynamics of the diurnal secretion of the three hormones in five anorectic patients. All of them reached a BMI of $17.5 \mathrm{~kg} / \mathrm{m}^{2}$ as the minimal weight criterion for $\mathrm{AN}$ according to the Diagnostic Manual of Mental Disorders, DSM-IV (22) during their inpatient treatment.

\section{Subjects and methods}

\section{Clinical research protocol}

Eleven anorectic patients and 11 under- and normalweight probands were studied after giving informed consent for a clinical research protocol approved by the Ethics Committee of the University of Essen (18). AN was diagnosed on the basis of the structured interview for anorexia nervosa and bulimia nervosa (SIAB) (23) which is a standardized interview for the assessment of eating disorders according to the DSM-IV (22).

From this cohort, hormone levels of five patients (1 male, 4 females) with AN (restricting type) in the state of semistarvation were studied twice: once after admission (T1) and once when the target body mass index (BMI) of $17.5 \mathrm{~kg} / \mathrm{m}^{2}$ was reached (T3). Four patients were also studied at time T2 (BMI $(\mathrm{T} 2)=(17.5+\mathrm{BMI}(\mathrm{T} 1)) \times 0.5)$. Age ranged from 22 to 31 years and the BMI at T1 from 13.15 to $15.10 \mathrm{~kg} /$ $\mathrm{m}^{2}$. All four female patients with AN were amenorrheic and none had received estrogens within the 3 months prior to the study. Apart from the eating disorder, clinical histories of concurrent illnesses could be excluded. Thyrotropin (TSH) levels of the patients were in the normal range and none of them received medications during the study period. According to the therapeutic and feeding regimen within the eating disorder unit, patients with AN were offered a balanced diet consisting of $2500 \mathrm{kcal} /$ day that was distributed as a breakfast buffet in the morning between $0730 \mathrm{~h}$ and $0830 \mathrm{~h}$ and as ready-to-eat meals for lunch and dinner between $1200 \mathrm{~h}$ and $1230 \mathrm{~h}$ and $1730 \mathrm{~h}$ and $1800 \mathrm{~h}$, respectively. Patients were requested to gain $0.5 \mathrm{~kg} /$ week.

\section{Sampling and hormone determinations}

Blood sampling was initiated at $2000 \mathrm{~h}$ via an indwelling venous catheter that had been inserted at $1900 \mathrm{~h}$; samples were collected every $2 \mathrm{~h}$ for $24 \mathrm{~h}$ totalling 12 samples per subject. Plasma samples were frozen at $-80^{\circ} \mathrm{C}$ prior to determination of leptin levels. Leptin levels were measured using a highly sensitive nonequilibrium version of a radioimmunoassay (sensitivity of $0.003 \mu \mathrm{l} / \mathrm{l}$ ) described previously in detail (24). The intra- and interassay coefficients of variation were 3.6 and $9.2 \%$ respectively. Insulin levels were determined by RIA (Insulin-CT, CIS Bio International, France) with an intra-assay coefficient of variation of $4.2 \%$ and a sensitivity of $2.0 \mu \mathrm{g} / \mathrm{l}$. Cortisol levels were measured using the Ciba Corning ACS Cortisol immunoassay with an intra-assay coefficient of variation of $5.7 \%$ and a sensitivity of $0.20 \mu \mathrm{g} / \mathrm{l}$.

\section{Statistics}

Mean leptin, insulin and cortisol concentrations within the $24 \mathrm{~h}$ period were computed for each patient. Data are expressed as means \pm S.D. or range. Correlation analyses were performed using Pearson product moment correlation coefficient. For all hormone values, areas under the curve (AUC) were computed using the parallelogram method. Group comparisons were performed with analysis of variance (ANOVA) followed by an unpaired Student's $t$-test as appropriate. Comparisons of values during the time course of refeeding (T1 to T3) were performed using ANOVA for repeated measures in those four subjects with complete data for T1 and T3. Significant differences were assumed at the $5 \%$ level. In addition, comparison of values for T1 and T3 was performed in those 4 patients with available data using Student's paired t-test. As data were not normally distributed, analysis was done after logarithmic transformation which yielded better normalization (skewness ranged from a maximum of 1.2 to $<0.7$ ).

Hormone profiles were subjected to cross-correlation analysis (leptin values against insulin and cortisol values) as described previously with minor modifications (18). In short, one set of data was fixed on the time axis, the second profile was shifted towards increasing time points (positive phase shift) or towards decreasing time points (negative phase shift). Shifting interval length equaled blood sampling interval length $(2 \mathrm{~h})$. 
A

T1
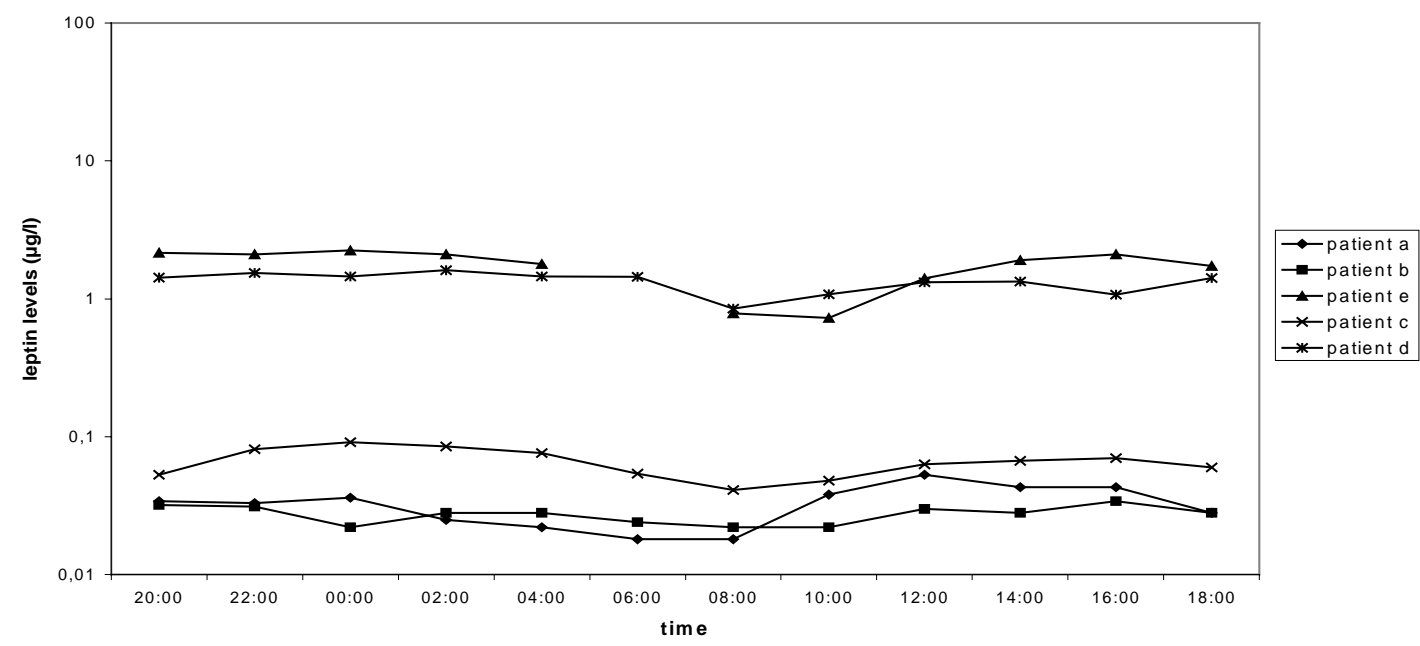

B

T2

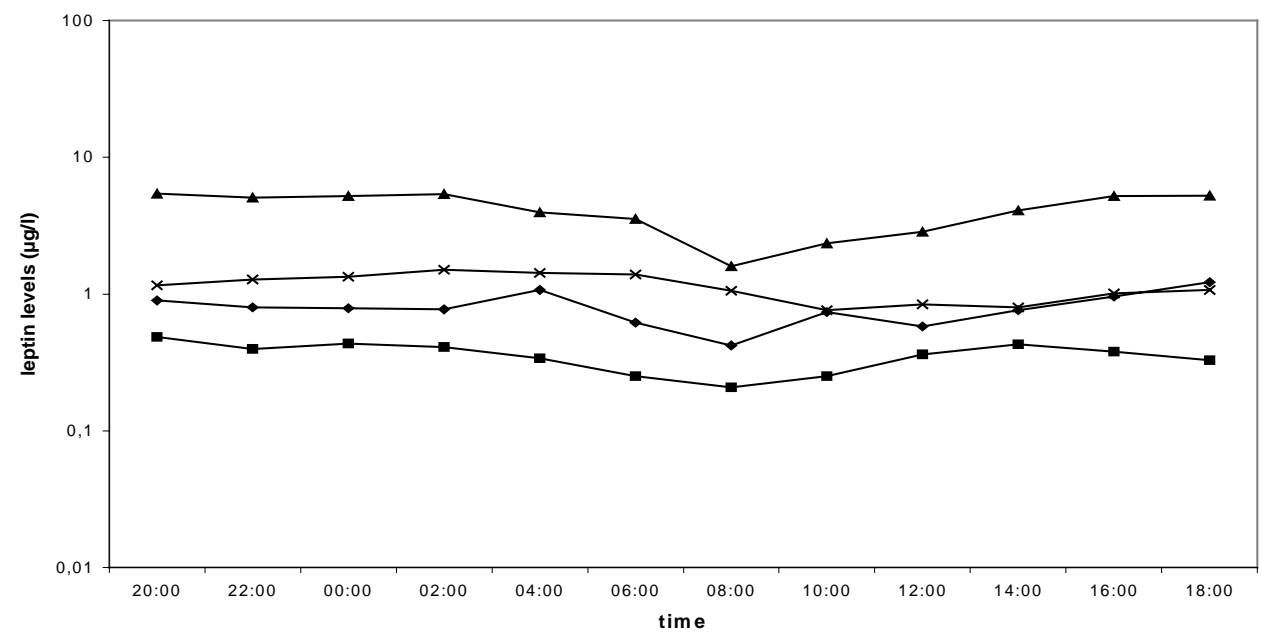

$\rightarrow$ patient a

- patient b

- patient e

$\rightarrow$ patient c

C

T3

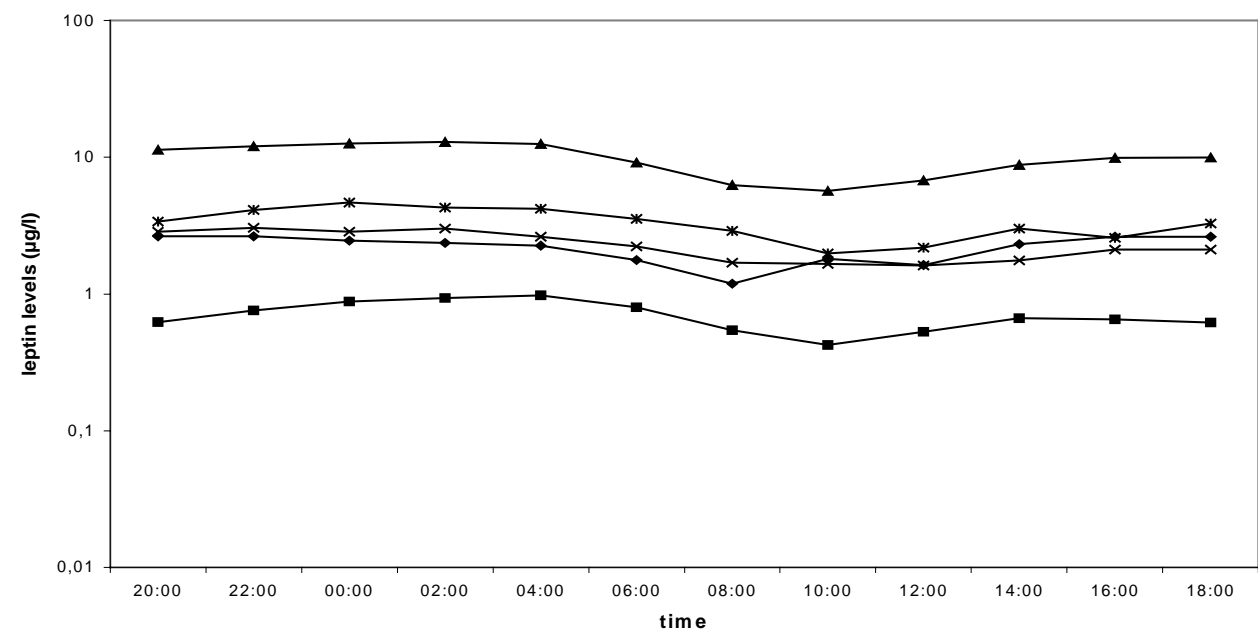

$\rightarrow$ patient a

$\rightarrow-$ patient b

$\rightarrow$ patient c

*-patient d

Figure 1 Leptin levels of five anorectic patients over a period of $24 \mathrm{~h}$ at three different weight levels. T1: at admission in the state of semistarvation, five patients $(A)$; T3: at target-BMI of $17.5 \mathrm{~kg} / \mathrm{m}^{2}$; five patients $(C)$; T2: after reaching half the target-BMl; four patients $(B)$. Please note the logarithmic scale of the $y$-axis and the expanded range at T3. 
For each phase shift, the correlation coefficent $r$ was calculated. Once the cross-correlation had been calculated for each subject, a mean correlation coefficent $R$ for every phase shift was computed for both groups of subjects. These mean $R$ values with their respective standard deviations were plotted against the phase shift. A significant departure of the mean correlation from 0 was assumed if correlation coefficients were outside the 95\% confidence interval defined by $-1 / N \pm 2 /\left(N^{-2}\right)(25)$. Calculations were performed using Excel (Microsoft, USA) and StatView 5.0 (SAS Institute, USA) on an Apple Power Macintosh computer.

\section{Results}

Within the whole sample of 22 anorectic patients and under- and normal-weight healthy probands the relationship of leptin to BMI showed a significant correlation $(r=0.585 ; P=0.004)$. Although the BMI of the five anorectic patients who took part in the longitudinal study ranged from only 13.15 to $15.0 \mathrm{~kg} / \mathrm{m}^{2}$ at $\mathrm{T} 1$, mean serum leptin levels showed large differences. Three patients had exceedingly low leptin levels with a mean between 0.03 and $0.06 \mu \mathrm{g} / \mathrm{l}$, while two other patients had mean values of 1.3 and $1.7 \mu \mathrm{g} / \mathrm{l}$, close to the range of underweight, non-anorectic patients (18). Despite this heterogeneity, values increased drastically in all patients. Conversely, mean cortisol levels decreased from $425 \mu \mathrm{g} / \mathrm{l}$ (range: $334-$ $601 \mu \mathrm{g} / \mathrm{l})(\mathrm{T} 1)$ to $336 \mu \mathrm{g} / \mathrm{l}$ (range: 307-404 $\mu \mathrm{g} / \mathrm{l})(\mathrm{T} 2)$ and to $274 \mu \mathrm{g} / \mathrm{l}$ (range: $196-336 \mu \mathrm{g} / \mathrm{l}$ ) (T3).

Figure 1 shows the $24 \mathrm{~h}$ leptin secretion patterns of the five anorectic patients during refeeding (T1 to T3, data of one patient at $\mathrm{T} 2$ are missing).

At $\mathrm{T} 1$ the five anorectic patients in the state of semistarvation showed the lowest mean leptin levels at $0800 \mathrm{~h}$ (mean: $0.34 \mu \mathrm{g} / \mathrm{l}$, range: $0.02-0.85 \mu \mathrm{g} / \mathrm{l}$ ) and the highest levels at $0200 \mathrm{~h}$ (mean: $0.77 \mu \mathrm{g} / \mathrm{l}$, range: $0.03-2.1 \mu \mathrm{g} / \mathrm{l}$ ) (Fig. 1A). At T2 the BMI of the four anorectic patients in the state of refeeding ranged from 15.40 to $16.70 \mathrm{~kg} / \mathrm{m}^{2}$ with the lowest levels at $0800 \mathrm{~h}$ (mean: $0.82 \mu \mathrm{g} / \mathrm{l}$, range: $0.21-1.59 \mu \mathrm{g} / \mathrm{l}$ ) and the highest levels at $0200 \mathrm{~h}$ (mean: $2.02 \mu \mathrm{g} / \mathrm{l}$, range: $0.41-5.39 \mu \mathrm{g} / \mathrm{l}$ ) (Fig. 1B). At T3, the lowest levels could be detected at $0800 \mathrm{~h}$ (mean: $2.52 \mu \mathrm{g} / \mathrm{l}$, range: $0.54-6.25 \mu \mathrm{g} / \mathrm{l}$ ) and the highest levels at $0200 \mathrm{~h}$ (mean: $4.70 \mu \mathrm{g} / \mathrm{l}$, range: $0.94-12.92 \mu \mathrm{g} / \mathrm{l}$ ) for all five anorectic patients (Fig. 1C). Because values at T2 were not available in one patient, ANOVA analysis was confined to four patients. Table 1 shows the strong increase of leptin values throughout the refeeding period.

Leptin levels and leptin AUCs increased significantly $(P=0.012$ and $P=0.011$, respectively, Student's paired $t$-test on log-transformed data). Cortisol levels and AUCs decreased, barely missing statistical significance $(P=0.082$ and $P=0.091$ respectively), while insulin levels did not change.
Table 1 Mean increases of leptin, cortisol and insulin levels in five anorectic patients during acute starvation (T1) and during the period of refeeding with increasing BMI (T2 and T3, details in text). Individual values were transformed to percentages of the T1 levels. Analysis by ANOVA for repeated measures was followed by Fisher's PLSD to describe the probability of a true departure (increase or decrease) from the initial value of $\mathrm{T} 1$.

\begin{tabular}{lcccc}
\hline Hormone & $\begin{array}{c}\text { T1 } \\
(\% \mathrm{~T} 1)\end{array}$ & $\begin{array}{c}\text { Mean T2 } \\
(\% \mathrm{~T} 1)\end{array}$ & $\begin{array}{c}\text { Mean T3 } \\
(\% \mathrm{~T} 1)\end{array}$ & $\begin{array}{c}\text { Mean ANOVA } \\
\boldsymbol{P} \text { value }\end{array}$ \\
\hline Leptin & 100 & $1430 \pm 910$ & $3340 \pm 2520$ & 0.033 \\
Cortisol & 100 & $88 \pm 4$ & $76 \pm 8$ & 0.004 \\
Insulin & 100 & $98 \pm 40$ & $130 \pm 83$ & n.s. \\
\hline
\end{tabular}

n.s., not significant with $P>0.05$.

Cross-correlation analysis of leptin and insulin revealed no significant correlation at $\mathrm{T} 1, \mathrm{~T} 2$ and $\mathrm{T} 3$ (Fig. 2), but leptin increases tended to follow insulin increases by $6 \mathrm{~h}$ at all three points in time. Statistical significance was narrowly missed for T2 at a lag of $6 \mathrm{~h}$. The cross-correlation profiles were similar to profiles published earlier (18). For the leptin/cortisol crosscorrelation no significant coefficients were obtained at $\mathrm{T} 1$, while at refeeding, the profile changed from $\mathrm{T} 2$ to T3. At T3, a strong inverse correlation between cortisol and leptin was observed at a lag of zero and $2 \mathrm{~h}$ (correlation coefficients -0.672 and -0.783 , respectively, the $95 \%$ confidence interval limit being -0.661). A tendency to a positive correlation between leptin and cortisol was seen at a lag of $-8 \mathrm{~h}$, i.e. leptin increases preceded cortisol increases by $8 \mathrm{~h}$ with a relatively large interindividual variation (Fig. 2).

\section{Discussion}

Multiple hormonal disturbances in AN have been well described (26-28). Very low leptin levels during starvation were documented by several authors (12-16). Within our sample of 22 anorectic patients and probands of under- and normal-weight, leptin levels correlated with the BMI.

In this study, we examined for the first time the longitudinal changes of leptin, insulin and cortisol levels in anorectic patients during the transition from the state of starvation to the state of refeeding, defined by the attainment of a BMI of $17.5 \mathrm{~kg} / \mathrm{m}^{2}$. All patients were studied at an intermediate point of this transition, arbitrarily defined by the acquisition of $50 \%$ of the difference between the individual baseline and the target BMI. This study design enabled us to evaluate changes in hormone levels in a longitudinal fashion. Only with this design was ANOVA analysis of repeated measures possible, increasing the statistical impact of the data collected. Leptin levels increased in a BMI-dependent fashion as T2 levels were intermediate between $\mathrm{T} 1$ and $\mathrm{T} 3$, supporting the notion of leptin being a signal generated by the increasing 


\section{A Leptin/Insulin}

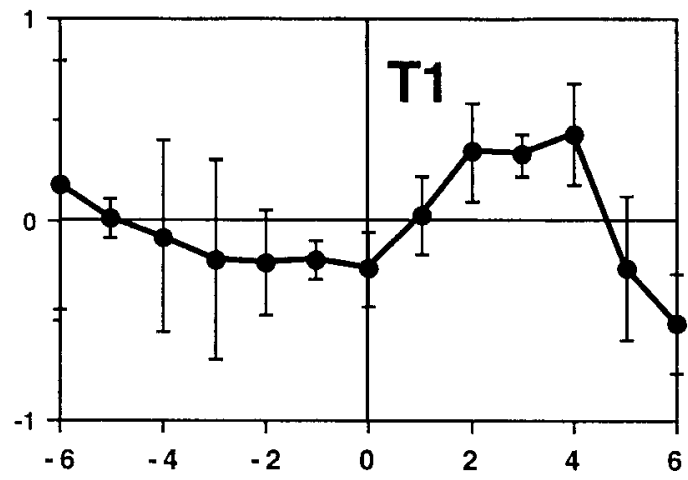

$B$

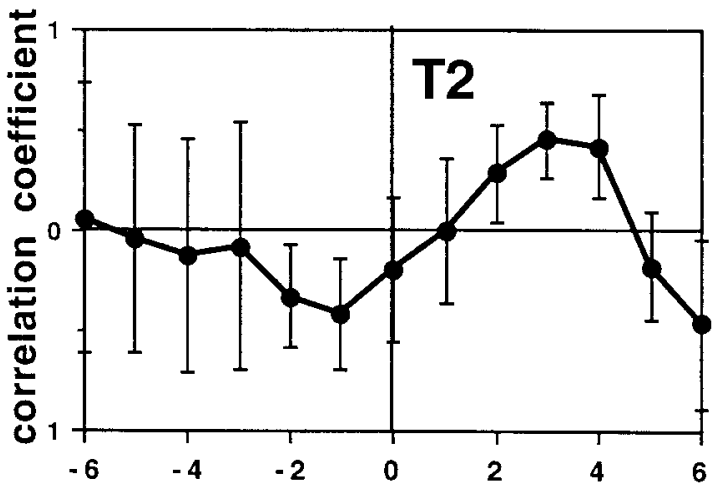

$c$

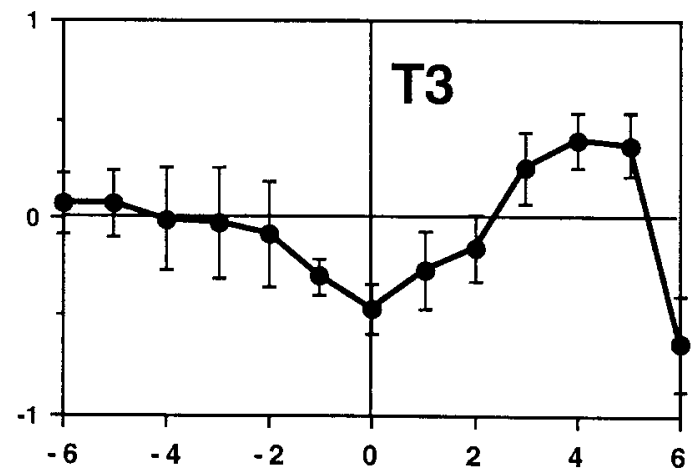

$D$

Leptin/Cortisol

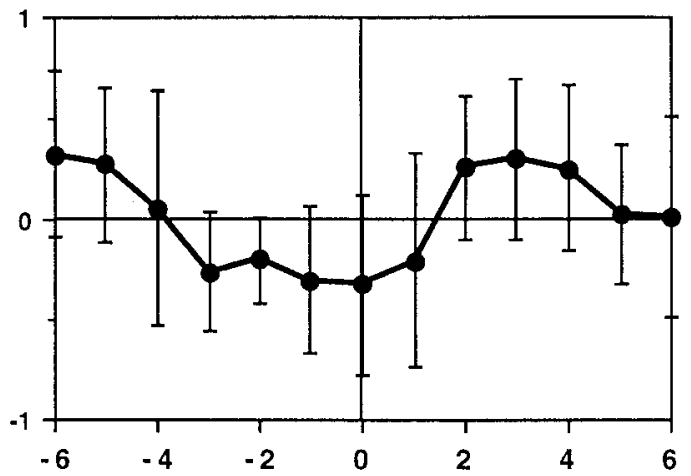

$E$

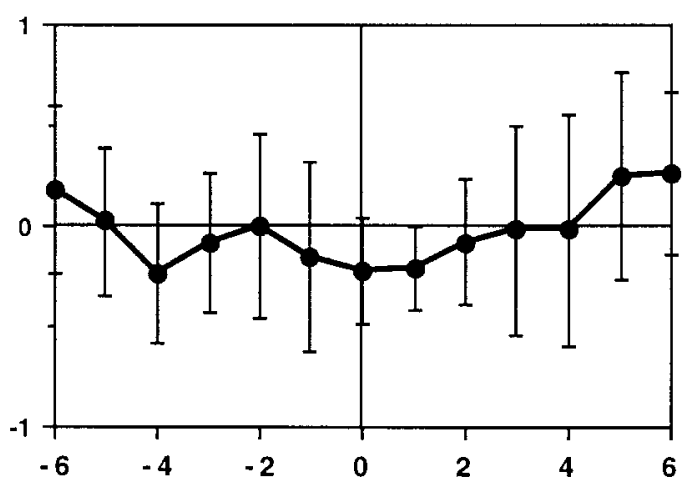

$F$

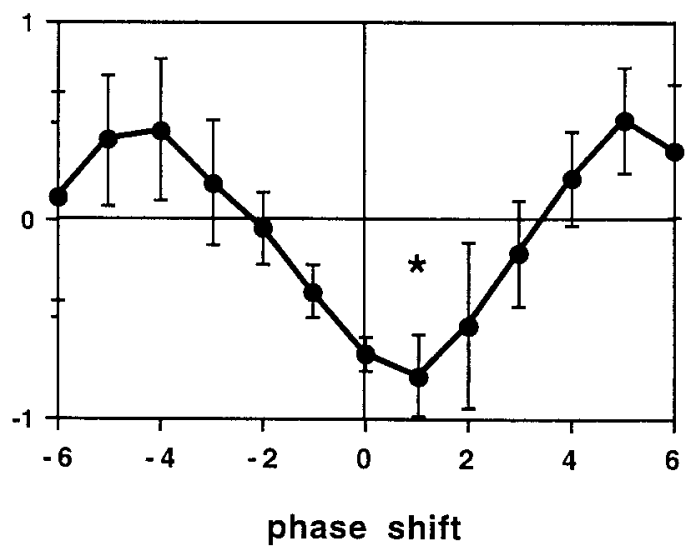

Figure 2 Cross-correlograms for leptin/insulin $(A-C)$ and leptin/cortisol $(D-F)$ in patients with anorexia nervosa. The correlation coefficient $r$ between the two hormone series is depicted on the $y$-axis at 0 on the $x$-axis. If the hormone series are shifted against each other by one sampling interval, the correlation coefficient changes. This situation is shown at phase shift ' 1 ' on the $x$-axis (the second hormone has been shifted by one sampling interval, the correlation has been recalculated). Further shifting of the hormone series by single sampling intervals gives rise to different $r$ values as shown in the graph. For better readability, the data points have been connected with a line. Correlation coefficients are shown as $r \pm 1$ S.D. If the second hormone (insulin or cortisol) is shifted to the opposite side, the phase shift is negative. As the sampling interval equaled $2 \mathrm{~h}$, each phase shift unit is $2 \mathrm{~h}$. Thus, a phase shift of 3 units equals a phase shift of $6 \mathrm{~h}$. Shown are cross-correlograms of leptin/insulin (left hand graphs) and of leptin/cortisol (right hand graphs) from the state of semistarvation (T1) through refeeding at T2 and T3 (see text for exact definition of T2 and T3). Data at time points T1 and T3 stem from one cohort of five patients studied sequentially. From one patient, data at T2 are missing, thus T2 represents data from only four patients. Note that for leptin/insulin and for leptin/cortisol the pattern of the correlogram does not change qualitatively, although a quantitative change emerges at T3. Significant levels were reached at leptin/cortisol T3 $(P<0.05$ with $r$ below -0.661 , statistics see text). 
fat mass. Although leptin levels oscillate in a circadian fashion $(18,20)$, the substantial increases in leptin during refeeding in AN were only achieved over a period of about 8 weeks for the first period (T1-T2) and another 10 weeks for the second period (T2-T3). Although these time lags were similar to those of Casanueva et al. (29) we could not confirm their assumption of a BMI level below which leptin levels do not drop further but also do not increase despite weight gain.

The intraindividual leptin secretion dynamics during the course of refeeding up to a BMI of $17.5 \mathrm{~kg} / \mathrm{m}^{2}$ yielded an almost uniform secretion pattern at all three weight levels with maximal values around $0200 \mathrm{~h}$ and minimal values around $0800 \mathrm{~h}$. These circadian variations are in line with $24 \mathrm{~h}$ studies on leptin secretion in normal weight individuals published previously $(16,20)$. However, contrary to the results of Balligand et al. (16) who postulated a complete abolition of circadian variation in anorectic patients, our results support a preservation of diurnal secretion patterns even in the severe state of emaciation. One explanation of these controversial findings may be the insufficient sensitivity of the leptin RIA $(0.5 \mu \mathrm{g} / \mathrm{l})$ used by Balligand et al. (16) and their $8 \mathrm{~h}$ intervals of leptin measurement.

In our study, cortisol levels decreased during refeeding in a BMI-dependent fashion with intermediate T2 levels. The hypercortisolism with elevated corticotrophin-releasing hormone (CRH) levels in CSF and blunted ACTH responses to $\mathrm{CRH}$ is not specific for AN. The up-regulation in the hypothalamo-pituitary-adrenal axis is probably a consequence of nutritional factors and starvation. It most likely reflects a suprapituitary effect at or above the hypothalamus $(28,30,31)$ and already normalizes after only small weight gains (26). It may be hypothesized that a negative feedback between leptin and cortisol secretion also exists in humans, similar to rodents, and is effective at both the hypothalamo-pituitary level and the adrenals. Alternatively, cortisol levels are regulated independently of leptin and decrease due to the lessening of the stress situation of starvation. We favor the first hypothesis, as we have shown in a previous study (18) and also in this paper that cortisol and leptin are negatively correlated on a short-term, ultradian basis. Insulin levels increased during refeeding, but due to a wide interindividual variation and a lack of an increase from $\mathrm{T} 1$ to $\mathrm{T} 2$, statistical significance was not reached.

Another aim of our study was to determine the temporal relationship between leptin and cortisol as well as insulin. We have previously demonstrated a positive, time-delayed relationship of leptin and insulin with insulin peaks preceding (and stimulating?) leptin increases (18). In the present study this relationship could be observed qualitatively at all three states of nutrition (T1-T3); however, no significant correlation could be obtained. Conversely, a temporal relationship between leptin and cortisol could not be demonstrated at starvation, but it emerged during refeeding, reaching significance only at T3, i.e. a BMI of $17.5 \mathrm{~kg} / \mathrm{m}^{2}$. Our present results differ only slightly at T1 from our previous findings (18). The negative relationship around a phase shift of $-6 \mathrm{~h}$ was preserved as was the positive relationship at a phase shift of +4 to $+6 \mathrm{~h}$. Only around 0 phase shift was a tendency towards negative correlations observed in this study, while values were positive in the previous sample. As none of the correlation coefficients were significantly different from zero, this difference is probably due to interindividual variations, as patients studied in these two experiments were not totally identical. This finding points to a pronounced but reversible disturbance of the relationship between cortisol and leptin in AN. It remains unclear if this disturbance contributes to the disease or if it follows on from the multiple pathophysiological changes in anorexia.

\section{References}

1 Zhang Y, Proenca R, Maffei M, Barone M, Leopold H \& Friedman JM. Positional cloning of the mouse obese gene and its human homologue. Nature 1994372 425-432.

2 Pelleymounter MA, Cullen MJ, Baker MB, Hecht R, Winters D, Boone $\mathrm{T}$ et al. Effects of the obese gene product on body weight regulation in ob/ob mice. Science 1995269 540-543.

3 Halaas JL, Gajiwala KS, Maffei M, Cohen SL, Chait BT, Rabinowitz D, et al. Weight-reducing effects of the plasma protein encoded by the obese gene. Science 1995269 543-546.

4 Campfield LA, Smith FJ, Guisez Y, Devos R \& Burn P. Recombinant mouse ob protein: evidence for a peripheral signal linking adiposity and central neural networks. Science 1995 $269546-549$.

5 Montague CT, Farooqi IS, Whitehead JP, Soos MA, Rau H, Wareham NJ et al. Congenital leptin deficiency is associated with severe early-onset obesity in humans. Nature 1997387 903-908.

6 Chen H, Charlat O \& Tartaglia LA. Evidence that the diabetes gene encodes the leptin receptor: identification of a mutation in the leptin receptor gene in $\mathrm{db} / \mathrm{db}$ mice. Cell 199684 491-495.

7 Clement K, Vaisse C, Lahlou N, Cabrol S, Pelloux V et al. A mutation in the human leptin receptor gene causes obesity and pituitary dysfunction. Nature 1998392 330-331.

8 Boden G, Chen X, Mozzoli M \& Ryan I. Effect of fasting on serum leptin in normal human subjects. Journal of Clinical Endocrinology and Metabolism 199681 3419-3423.

9 Sinha MK, Ohannesian JP, Ohannesian JP, Heimann ML, Kriauciunas A, Stephens TW et al. Nocturnal rise of leptin in lean, obese, and non-insulin-dependent diabetes mellitus subjects. Journal of Clinical Investigation 199697 1344-1347.

10 Kolaczynski JW, Nyce MR, Considine RV, Boden G, Nolan JJ, Henry $\mathrm{R}$ et al. Acute and chronic effects of insulin on leptin production in humans: studies in vivo and in vitro. Diabetes 1996 45 699-701.

11 Considine RV, Madhur K, Heiman M, Kriauciunas A, Stephens TW, Nyce, MR et al. Serum immuno reactive-leptin concentrations in normal-weight and obese humans. New England Journal of Medicine 1996334 292-295.

12 Hebebrand J, van der Heyden J, Devos R, Köpp W, Herpertz St, Remschmidt $\mathrm{H}$ et al. Plasma concentrations of obese protein in anorexia nervosa. Lancet 1995346 1624-1625.

13 Grinspoon S, Gulick T, Askari H, Landt M, Lee K, Anderson E et al. Serum leptin levels in women with anorexia nervosa. Journal of Clinical Endocrinology and Metabolism 199681 3861-3863. 
14 Ferron F, Considine RV, Peino R, Lado IG, Dieguez C \& Casanueva FF. Serum leptin concentrations in patients with anorexia nervosa, bulimia nervosa and non-specific eating disorders correlate with the body mass index but are independent of the respective disease. Clinical Endocrinology 199746 289-293.

15 Eckert ED, Pomeroy C, Raymond N, Kohler PF, Thuras P \& Bowers CY. Leptin in anorexia nervosa. Journal of Clinical Endocrinology and Metabolism 199883 791-795.

16 Balligand JL, Brichard SM, Brichard V, Desager JP \& Lambert M. Hypoleptinemia in patients with anorexia nervosa: loss of circadian rhythm and unresponsiveness to short-term refeeding. European Journal of Endocrinology 1998138 415-420.

17 Sinha MK, Ohannesian JP, Kriauciunas A, Stephens TW, Magosin S, Marco C et al. Nocturnal rise of leptin in lean, obese, and non-insulin-dependent diabetes mellitus subjects. Journal of Clinical Investigation 199697 1344-1347.

18 Herpertz S, Wagner R, Albers N, Blum WF, Pelz B, Langkafel M et al. Circadian plasma leptin levels in patients with anorexia nervosa. Relation to insulin and cortisol. Hormone Research 1998 50 197-204.

19 Saladin R, De Vos P, Guerre-Millo M, Leturque A, Girard J, Staels B et al. Transient increase of obese gene expression after food intake or insulin administration. Nature 1995377 527-529.

20 Licinio J, Mantzoros C, Negrae AB, Cizza G, Wong ML, Bongiorno $\mathrm{PB}$ et al. Human leptin levels are pulsatile and inversely related to pituitary-adrenal function. Nature Medicine $19973575-579$.

21 Licinio J, Negrao AB, Mantzoros C, Kaklamani V, Wong M.-L., Bongiorno PB et al. Synchronicity of frequently sampled, 24-h concentrations of circulating leptin, luteinizing hormone, and estradiol in healthy women. Proceedings of the National Academy of Sciences of the USA 199895 2541-2546.

22 American Psychiatric Association. Diagnostic and Statistical Manual of Mental Disorder: DSM-IV. 4th edn. Washington DC: American Psychiatric Association 1994.

23 Fichter MM, Herpertz St, Quadflieg N \& Herpertz-Dahlmann B. Structured interview for anorexic and bulimic disorders SIAB-EX for DSM-IV and ICD: updated (3rd) revision. International Journal of Eating Disorders 199824 227-249.

24 Blum W, Englaro P, Hanitsch S, Juul A, Hertel NT, Müller J et al. Plasma leptin levels in healthy children and adolescents: dependence on body mass index, body fat mass, gender, pubertal stage, and testosterone. Journal of Clinical Endocrinology and Metabolism 199782 2904-2910.

25 Chatfield C. Estimation in the time domain. In Analysis of Time Series, edn 5, pp 49-65. Ed C Chatfield. London: Chapman \& Hall 1996.

26 Fichter MM, Doerr P, Pirke KM \& Lund R. Behavior, attitude, nutrition and endocrinology in anorexia nervosa. Acta Psychiatrica Scandinavica $198266429-444$.

27 Halmi KA. Basic biological overview of eating disorders. In Psychopharmacology: the Fourth Generation of Progress, pp 16091616. Eds FE Bloom \& DJ Kupfer. New York: Raven Press, 1995.

28 Kaye WH, Gwirtman HE \& George DT. Elevated cerebral spinal fluid levels of immunoreactive corticotropin-releasing hormones in anorexia nervosa: relation to state of nutrition, adrenal function, and intensity of depression. Journal of Clinical Endocrinology and Metabolism 198764 203-208.

29 Casanueva FF, Dieguez C, Popovic V, Peino R, Considine RV \& Caro JF. Serum immunoreactive leptin concentrations in patients with anorexia nervosa before and after partial weight recovery. Biochemical and Molecular Medicine 199760 116-120.

30 Gold PW, Gwirtman H, Avgerinos PC, Nieman LK, Gallucci WT, Kaye W et al. Abnormal hypothalamic-pituitary-adrenal function in anorexia nervosa. The New England Journal of Medicine 1986 414 1335-1342.

31 Hotta M, Shibasaki T, Masuda A, Imaki T, Demura H, Ling N et al. The responses of plasma adrenocorticotropin and cortisol to corticotropin-releasing hormone ( $\mathrm{CRH}$ ) and cerebrospinal fluid immunoreactive $\mathrm{CRH}$ in anorexia nervosa patients. Journal Clinical Endocrinology and Metabolism 198662 319-324.

Received 10 May 1999

Accepted 25 November 1999 